Acta Universitatis Wratislaviensis No 3920

Anglica Wratislaviensia LVII, Wrocław 2019

DOI: $10.19195 / 0301-7966.57 .8$

\author{
Corina Selejan \\ ORCID: 0000-0002-4418-7087 \\ Lucian Blaga University of Sibiu \\ corina.selejan@ulbsibiu.ro
}

\title{
Fragmentation(s) and Realism(s): Has the Fragment Gone Mainstream?
}

\begin{abstract}
This article tackles what seems to be a revival of fragmentary fiction in English in the 21 st century. It briefly traces the lineage of critical interest in the fragment from German Romanticism through Bertolt Brecht and Modernism to (postmodern) film studies, in an attempt to highlight not only the temporal, but also the spatial and visual dimension of discontinuity evinced by recent fragmentary fiction. Six novels published between 2005 and 2017 are discussed sequentially, in a manner redolent of cinematic movement: Tom McCarthy's Remainder (2005), Anne Enright's The Gathering (2007), Yaa Gyasi's Homegoing (2016), Mohsin Hamid's Exit West (2017), Ali Smith's Autumn (2016), and George Saunders's Lincoln in the Bardo (2017). The formal fragmentariness of these novels is read in connection to their recurrent themes: trauma, loss, death, grief, exile, displacement, memory and violence. In the process, the opposition between fragmentariness on the one hand and realism on the other is challenged; the argument draws on William Burroughs, Tom McCarthy and Fernand Léger. Although they are fragmentary in very different ways, all of the novels under scrutiny are what one may term "mainstream" novels, most of them boasting large readerships and having either won or been shortlisted for literary prizes such as the Booker Prize, thus seemingly confirming Ted Gioia's contention that "mainstream literary fiction is falling to pieces".
\end{abstract}

Keywords: fragmentary fiction, recent mainstream fiction, realism, film studies, discontinuity

First, a caveat: although "realism" and "fragmentariness" are widely used cultural concepts, neither is to be treated as a homogeneous phenomenon, hence the bracketed plurals in the title. In an attempt to do justice to the diversity of the fragmentariness evinced by recently published fiction in English, this article tackles six novels in a sequential manner: Tom McCarthy's Remainder (2005), Anne Enright's The Gathering (2007), Yaa Gyasi's Homegoing (2016), Mohsin Hamid's Exit West (2017), Ali Smith's Autumn (2016), and George Saunders's Lincoln in the Bardo (2017). While the order of the novels' discussion seems to be dictated by their dates of publication, the rationale behind this arrangement relates to recurrent themes and motifs - such as death, loss, exile, and displacement - as well as to 
common stylistic traits, such as the narrative handling of time and space. Moreover, the sequence is the result of a sense of increasing fragmentation, from the subdued thematic fragmentariness of Remainder to the radical polyphony and typographic unrest of Lincoln in the Bardo. Most importantly, the discussion of several novels in one article was felt as a necessity: the more (culturally) diverse and broader the basis of discussion, the more confident the generalizing claim that the fragment has indeed gone mainstream, i.e. that recent mainstream fiction tends to incorporate formal and narrative techniques that were formerly relegated to the domain of the avant-garde.

Throughout this article, reference will be made to the visual arts and to cinema in particular, as the idea of wholeness and unity versus fragmentation and heterogeneity seems to have been a much more prominent one in film studies than in literary studies: the concept of the "continuity style" (Kolker 15; Ray 68)-also known as "continuity editing" (Sikov 61; Dyer 5) and "classical Hollywood style" (Kolker 16) - pervades film studies. The continuity style posits itself as a standard against which all other editing styles are measured and to which they are compared even as it is repudiated by its critics. The same holds true for the way the realism of 19th-century novels in Western literature has been constructed as a norm and has come to be inextricably bound to the novel as a genre. Of late, the continuity style in film-i.e. a self-effacing style of montage that seeks to obscure the cuts and discontinuities between shots - has come under critical fire for creating an illusion akin to the one literary realism aspires to: the linear and teleological progression of the action, spatial and temporal continuity, and the illusion of character as a unity, as a "whole". In short, "an attempt to cover over the cracks between film fragments in just the same way that mass culture seeks to weld a unity out of the fragmentation of modern societies" (Dyer 5, my italics).

However, the seeming hegemony of the fragment in film studies as opposed to literary studies needs to be taken with a grain of salt, particularly when one harks back to the early Romantics in Germany, to August Wilhelm and Friedrich Schlegel and their attempt to raise the fragment to the status of a literary genre by emphasizing its openness and lack of self-sufficiency, its potential to make the reader participate more actively in the consumption as much as the creation of the literary text - a tradition inherited and expanded by Bertold Brecht in his "theatre of interruptions" as well as by Modernism at large. More recently, in December 2014, McCarthy took issue with realism and the real and recuperated Ford Madox Ford's and William Burroughs's stances towards the real —in particular Burroughs's wellworn dictum "Consciousness is a cut-up; life is a cut-up" (Burroughs 76, italics in the original) - to argue that "the 20th-century avant-garde often paints a far more realistic picture of experience than the 19th-century realists ever did" (McCarthy "Writing"). McCarthy's own novel Remainder devotes an intensity of attention to material details - to fragments of reality. The novel thereby educates the reader's own attention to the material world and might be termed neo-modernist if we cared 
to reduce it to a label. A crack in a bathroom wall, "the way it ran down the wall, the texture of the plaster all around it, the patches of color to its right" (60) all trigger a memory in the nameless protagonist's mind that comes to underpin his entire life, or, in other terms, the whole novel. This intensity of attention to objects is reminiscent of Fernand Léger's 1926 manifesto "A New Realism-The Object (Its Plastic and Cinematic Graphic Value)", which affirms the power of the fragment and advocates its use in cinema through "close-ups of the largest possible scale", as well as through heightened attention to light and shade and through the speed of projection. Not surprisingly, the spectacular effect such a cinematic treatment of isolated objects yields is yet again linked to realism: "The realism of the cinema is yet to be created" (Léger). McCarthy's enactor-protagonist too feels that only in the spaces conjured up by these minutest material details "all [his] movements had been fluent and unforced. Not awkward, acquired, second-hand, but natural ... seamless, perfect. ... They'd been real; [he]'d been real" (60). This reality hunger is what drives the protagonist to reconstruct the remembered building and re-enact the remembered actions. On closer inspection, the (re-)enactor's actions are akin to those of the writer of fiction: both closely observe the reality around them in order to re-enact it, to re-create it - in this case ultra-mimetically — in another medium. Yet in his hopeless quest for authenticity, McCarthy's re-enactor consistently refuses a medium, banning cameras from the "sets" of his re-enactments (or re-enactments of re-enactments, meta-re-enactments as it were). McCarthy's novel illustrates a kind of fragmentariness that is not formal or not primarily so, for Remainder reads very much like a traditionally linear narrative, without the affect that customarily characterizes it. Incongruously — one feels - this affect-less language and deadpan narration is effected in the first person - in Zadie Smith's words, "in a straightforward first person that reminds us that most avant-garde challenges to realism concentrate on voice, on where this 'I' is coming from" (85). First-person narration is conspicuously present in half of the novels discussed here, which is surprising, at least at first sight, given the fact that fragmentariness is more readily associated with multiple voices. As we shall see in the discussion of Saunders' novel Lincoln in the Bardo, multiple voices often also translate into multiple I's.

The title of Enright's Booker-Prize-winning The Gathering hints not only at the gathering of the large Hegarty family for Liam's wake, but also at the "gathering of Liam-i.e. bringing him [his body] home from Brighton, but also recollecting a sense of what he was like" (Schneider 82), an undertaking his closest sister and the novel's first-person narrator Veronica fulfils ever so haltingly, interruptedly, at times reluctantly: "But let that wait" (41). The event that led to Liam's suicide is her brother's abuse - allegedly witnessed by Veronica in their childhood but never disclosed to the rest of the family or discussed with Liam himself - by a man in their grandmother's garage, narrated as such more than half-way into the novel: "It is time to put an end to the shifting stories and the waking dreams. It is time to call an end to romance and just say what happened in Ada's house, the year that 
I was eight and Liam was barely nine" (142). Veronica's "failure to empathize with Liam" (Schneider 81) and to come to terms with his suicide translates into a fractured form, a novel made up of disparate episodes, scenes, thoughts, moving restlessly through time and space.

The novel's chapters are often introduced by a straightforward "here is": "Here's Ada and Charlie" (56), "Here is another scene" (135), "Here is Ada" (230), "Here is my grandfather" (30), "So here they all are" (105), as if Veronica the narrator were unable to connect the threads that make up her incomplete family history, whose gaps she fills tentatively, unreliably, fictionally-admittedly and emphatically so. The fragmented quality of memory is thus made explicit in the presentification of all these scenes which demonstrably take place neither here, nor now, not in the present of the act of narration (self-reflexively and repeatedly flaunted: "as I write ..." $[132,146])$, much less in the present of the act of reading, which is also foregrounded in occasional metafictional remarks: "I can twist them as far as you like, here on the page" (139). These scenes take place in the here and now of memory. It is from this memory that the truth has to be unearthed: "The truth. The dead want nothing else. It is the only thing that they require" (156) - all the more so because "Liam's great talent"-Veronica remembers —was "exposing the lie" (125).

The Gathering constitutes itself a work of mourning, the mourning of loss, i.e. of "separation as rupture of communication - the deceased, someone who no longer answers - constitutes a genuine amputation of oneself to the extent that the relation with the one who has disappeared forms an integral part of one's self-identity" (Ricoeur 359). This amputation translates into Veronica's desire to put an end to the "untruths" of her own marriage: "I didn't seem to mind the inverted commas, or even notice that I was living in them, until my brother died" (Enright 181). Death emerges (not only in formal terms) as the grand interruption, the interruption par excellence. Drawing on Michel de Certeau, Ricoeur views writing about death as the equivalent of the social ritual of burial, an exorcism of sorts conducted by a historian (Ricoeur 367), and this is indeed what Veronica's discourse feels like, an exorcism of both death and her own guilt in not having told the truth about Liam's abuse while he was still alive. It is, however, a discourse that can only be fractured and intensely self-reflexive: of all the novels discussed in this essay, Enright's is the one most relentlessly inward-looking.

Loss is pivotal to Enright's novel, as it is to Gyasi's Homegoing, which follows the family histories of two half-sisters born in Ghana: Effia, who marries the British governor of Cape Coast Castle, and Esi, Effia's unknown half-sister, who is captured and then kept as a prisoner in that same castle's dungeons before being sent to America on a slave ship. Seven generations of descendants are then fleshed out, alternatively, by going back and forth from one sister's descendants to the other's, from one side of the family tree (placed at the beginning of the book) to the other, in what reads like a litany of love, loss, and unspeakable cruelty, written however 
with a remarkable, almost aphoristic, economy of language and in an affectively restrained, pathos-free manner. As Gyasi's self-imposed limit is 20 to 30 pages per character ("Yaa Gyasi"), the duration of each character's lifespan on the page is necessarily very short, so that the novel reads like a collection of fragments, in which the gaps, the absences are more conspicuous than the presences of the 250 years covered by its narrative. With each character who is left in mid-action, the reader is made to experience an acute loss akin to the familial losses endured by the characters themselves. However, as the narrated events grow ever more horrifying and the cruelty becomes unbearable-e.g. Sam's lynching witnessed by his whipped wife, Akua's setting fire to her family's hut and the resulting death of her two little daughters - the rapid pace of the narrative comes as a merciful relief to the reader who can comfort herself with the fact that for herself at least it will soon be over. This alternation of grief and relief is only made possible by the novel's episodic form. Gyasi mostly resists re-connecting all the threads and thereby satisfying the reader's curiosity, yet she does give in, finally, to the urge to fuse the fragments into a closure of sorts by making the descendants of the two sisters, a young woman and a man, meet in the U.S. and travel together to Ghana, to Cape Coast Castle.

In an interview, Gyasi admits that the structure took her about three years to devise and that it led to the discarding of no less than 100 pages written in the present of the latest generation, with flashbacks into the past ("Yaa Gyasi")-an apparently less linear approach to narrative time, but also a more overtly unifying and traditional scheme, with a strong teleological thrust. Harking back to Fernand Léger, Gyasi's novel would translate visually into a temporally and spatially vast darkness punctuated by luminous fragments, an interplay of light and shade that relinquishes its claim to completeness. The effect of the family tree at the beginning of the novel is, at first sight, unifying, linking the generations of Maame's descendants. However, during the process of reading, the reader is not only zigzagging between its two branches, but also between the text and the family tree itself, fulfilling a need to firmly place each character within the family, to remember who her forebears were, to impose order onto an accumulation of biographies. The reading of this novel illustrates Wolfgang Iser's point that texts

are often so fragmentary that one's attention is almost exclusively occupied with the search for connections between the fragments; the object of this is not to complicate the "spectrum" of connections, so much as to make us aware of the nature of our own capacity for providing links. In such cases, the text refers back directly to our own preconceptions-which are revealed by the act of interpretation that is a basic element of the reading process. (55, my italics)

Homegoing - concerned as it is with colonialism, the wars between the Fantes and Asantes, slavery, the Great Migration, Harlem and heroin addiction in the 1960s, Ghana's independence movement, education (or the lack of access to it) — is the very book to refer one back to one's own preconceptions of race, gender, sexuality, history, slavery, colonialism, and many other interconnected issues. Gyasi's novel posits itself as a recuperative effort: Yaw, a history professor, invites his 
students and the novel's reader to question history as the victor's story, as the story of the ones in power and the recent, all too loud discourse of forgiveness as a "trick" white Christians are playing while they go on "committing their wrongs" (237). Homegoing metafictionally discusses its genesis as lying in the desire "to capture ... the feeling of time, of having been part of something that stretched so far back, was so impossibly large, that it was easy to forget that she [Marjorie] and he [Marcus], and everyone else, existed in it — not apart from it, but inside of it" (295-96). Marcus, the African American descendant of Esi, feels overwhelmed by the history of slavery and racism in America, which he is trying to compress into his $\mathrm{PhD}$ dissertation. The solution to his problem, the novel suggests, is a change of genre.

Hamid's Exit West is a novel whose geography covers the whole planet-however fragmentarily - as its fictional fabric is strewn with very condensed vignettes of people from all over the world. Gyasi's handling of time mirrors Hamid's treatment of space. The vignettes in Exit West are made possible by a faintly sci-fi device: black doors which enable the people who enter to exit them in other parts of the world than their own, the passage through feeling much like a death followed by an exhausting birth on the other side. Migration and loss (the loss of one's family and home land) again take centre stage and the structure of the novel - the main story of Saeed and Nadia punctured by the vignettes - seems to reflect the fractured world of the present as well as the near future: "The news in those days was full of war and migrants and nativists, and it was full of fracturing too, of regions pulling away from nations, and cities pulling away from hinterlands, and it seemed that as everyone was coming together everyone was also moving apart" (155, my italics). Just as Homegoing leaves long spans of time in the dark, Exit West constructs the doors as being "darker than night, a rectangle of complete darkness - the heart of darkness" (6), a playful allusion to Conrad, followed three pages later by an equally facetious hint to Achmed the Dead Terrorist, ventriloquist Jeff Dunham's popular puppet character: "Location, location, location, the estate agents say" (9). Fragmentation pervades the novel, not least in its explicit affirmation of the multifaceted-ness of the self: "Every time a couple moves they begin, if their attention is still drawn to one another, to see each other differently, for personalities are not a single immutable color, like white or blue, but rather illuminated screens, and the shades we reflect depend much on what is around us" (186). This description too is redolent of Léger's cinematic manifesto, of the importance of the interplay of light and shade.

Revolving around the historical fracture represented by the Brexit referendum, Ali Smith's Autumn embodies fractured time par excellence: almost 40 time shifts are effected in its pages, spanning almost a century, from the pre-Holocaust 1930s to the post-Brexit autumn months of 2016, drawing parallels between the former and the latter, with many other events interspersed between the two. The complicated, zigzagging temporal scheme prompts the (attentive) reader to go over the 
post-Brexit 2016 calendar repeatedly, almost obsessively and thereby place the event firmly in time. The alert narrative rhythm is overtly qualified as such, implying both the compression of time in fiction and the fleeting quality of lived time: "Boy on a train. Blink of an eye. Old man in a bed" (101), or elsewhere: "It takes a fragment of a fragment of a second for Elisabeth's data to go into the computer" (111, my italics). The image of Daniel Gluck's flying watch as a literal enactment of "time flies" is another such instance. So is the characterization of news as "Thomas Hardy on speed" (39). The novel's artistic eclecticism is self-referentially summed up at one point, employing a term hailing from the visual arts: "Collage is an institute of education where all the rules can be thrown into the air, and size and space and time and foreground and background all become relative, and because of these skills everything you think you know gets made into something new and strange" (71-72).

The most unsettling novel to be discussed in this article is Saunders's Lincoln in the Bardo, the Man Booker Prize winner for 2017. The novel wears its fragmentariness and polyphony on its page, as its text consists exclusively of quotations belonging to 166 historical and fictional personae, resulting in frequent white spaces on the novel's pages, which thus take on the typographical appearance of the pages of a play rather than that of a novel. As several public readings from Saunders's novel suggest, the genre most readily associated with his text is drama - hence the many performers who are required for the readings. Unlike drama, however, this text insists on naming the persona who has been speaking or writing after its speech or quotation, thereby confusing the reader at the outset of the novel and signaling the fact that the text is not a play, but rather a chronicling document or artefact, a collage of quotations. Two voices stand out from the salmagundi of discourses, due to the fact that they are the first two characters to speak and due to the constancy of their presence: those of hans vollman and of roger bevins iii. The names of all the dead fictional personae in this novel are not capitalized, while the names of the authors of the historical sources and memoirs quoted in the novel are, whether they are real authors or invented ones. The text thereby implies that conventions such as the capitalization of proper names do not apply in the afterlife. Most of the characters inhabiting the cemetery where Willie Lincoln (i.e. willie lincoln), U.S. President Abraham Lincoln's beloved son, is laid to rest, are in denial about their actual state, employing such euphemisms as "sick-box" (5) for coffin, "sick-cart" (5) for hearse, "hospital-yard" (6) for cemetery and "sickform" (58) for corpse. Apart from the comic effect such obstinate fleeing in the face of their own condition has on the reader, these coinages also defamiliarize death for the reader. "Matterlightblooming" (96) is another example of Saunders's inventiveness with words; the term seems to mean the passing from the bardo, this purgatory-like space, into the afterlife proper, towards judgement by a divine authority, as the reverend everly thomas makes clear. What the entire novel enacts in its form as well as fictional world is indeed alien to all readers, since they have yet to experience death; nevertheless, a knowledge of religious (Christian) texts and conventions certainly 
helps the reader in navigating the narrative. The novel's formal eccentricity also takes a considerable time to adjust to, so much so that its apparently uncluttered pages do not translate into a quick or easy read. The quotations from (partly pseudo-) historical sources are helpfully divided from the first-person direct speech of the characters in the cemetery into separate chapters, yet they constantly interrupt the "narrative" and are alternatively vehicles of suspense and mild annoyance. However, the historical context of the Civil War, which is crucial to the moral dilemmas of the grieving President Lincoln (whose thoughts, read by the spirits which briefly inhabit him, are graphically set apart via italicization), could not otherwise be grasped by the reader. Significantly, the most harrowing and innovative novel discussed here also revolves around death and unspeakable grief.

There are many more twenty-first century novels that evince ever more diverse brands of fragmentariness, such as Andrew Crumey's Mr. Mee (2000), Denis Johnson's Train Dreams (2002), Nicola Barker's Clear: A Transparent Novel (2004), Nicole Krauss's The History of Love (2005) and Great House (2010), Nicholas Royle's First Novel (2013), Zadie Smith's NW (2012) and Swing Time (2016), Paul Auster's 4321 (2017). However, their fragmentariness is of a much quieter variety than, say, Christine Brooke-Rose's novels from the 1960s to the 1990s. Nevertheless, Christine Brooke-Rose was (regrettably but indisputably) not a mainstream novelist. All the novels touched upon in this essay have either been shortlisted for, or have won, literary prizes like the Man Booker Prize or the National Book Critics Circle John Leonard Award for first best book (Homegoing's case). Others are bestsellers, or else have been cast in extremely influential roles by critics - the case of Remainder, influentially hailed by Zadie Smith as the novel "to shake the novel out of its present complacency" (94) and constructed as the opposite of the "lyrical realism [that] has had the freedom of the highway for some time now, with most other exits blocked" (73). With a wary eye kept on the irreducible diversity of these novels, one can still safely assert that they qualify as mainstream literary fiction.

In his 2013 essay "The Rise of the Fragmented Novel: An Essay in 26 Fragments", Ted Gioia claims that "[m]ainstream literary fiction is falling to pieces" and that this is a positive development. However, he also asserts that "the new fragmented novel is holistic and coalescent. It resists disunity, even as it appears to embody it." Gioia is quick to proclaim the fact that in the contemporary novel experimentation is compatible with accessibility and that attention to form has come to dominate it, thus being somewhat at odds with other critics such as Patricia Waugh and Jennifer Hodgson, who maintain that British culture at least reads literary innovation as "degeneration" (10) or in other words that "literary experiment still tends to be perceived as a pernicious form of French flu" (11). While I agree with Gioia, Waugh and Zadie Smith up to a point, I maintain that the crucial point is that the contemporary novel is still — vitally — an embattled ground and that so is literary style. At the 2012 Edinburgh World Writers' Conference, Ali Smith delivered a talk entitled "Style vs. Content", followed by a heated discussion among 
the attending writers about the necessity to adapt one's style to the preferences of the reading public on the one hand, and "style's responsibilities and moralities" on the other (Ali Smith "Style"). Ali Smith and China Miéville were two of the novelists who upheld the importance of preserving one's style, in spite of its being difficult for the reader, while other writers openly voiced their concern with making ends meet. The novels selected for discussion in this article certainly justify Smith's and Miéville's position. However, one needs to bear in mind that this is no more than a non-arbitrary, deliberate selection and that although present critical discourse largely maintains the inherent realism of the fragment-realism not as a set of time-worn conventions but as that which is "truly" realistic - the question in the title "Has the fragment gone mainstream?" had better remain just that: an open question inviting answers and requiring the benefit of hindsight and larger critical consensus in order to become a statement of fact.

\section{References}

Burroughs, W. S. 2013. The Adding Machine. New York: Grove Press.

Dyer, R. 2011. "Introduction to Film Studies." In: Hill, J., and P. Church Gibson (eds.). Film Studies: Critical Approaches. Oxford: Oxford UP, 1-8.

Enright, A. 2008. The Gathering. London: Vintage.

Gioia, T. 2013, July 17. "The Rise of the Fragmented Novel: An Essay in 26 Fragments." Retrieved from http://fractiousfiction.com/rise_of_the_fragmented_novel.html. 10 Feb. 2017.

Gyasi, Y.. 2016, Dec. 5. "Yaa Gyasi: Homegoing" [Online video clip]. Retrieved from https://www. youtube.com/watch?v=LoEAWvTvFus. 1 Sept. 2017.

—. 2017. Homegoing. London: Penguin.

Hamid, M. 2017. Exit West. London: Hamish Hamilton.

Iser, W. 1980. "The Reading Process: A Phenomenological Approach.” In: Tompkins, J. P. (ed.). Reader-Response Criticism: From Formalism to Post-Structuralism. Baltimore: John Hopkins UP, 50-69.

Kolker, R. P. 2011. "The Film Text and Film Form.” In: Hill, J., and P. Church Gibson (eds.). Film Studies: Critical Approaches. Oxford: Oxford UP, 9-27.

Léger, F. 2015, Aug. 11. "A New Realism-The Object (Its Plastic and Cinematic Graphic Value)." Retrieved from https://www.flickeralley.com/a-new-realism-the-object-its-plastic-andcinematic-graphic-value/. 15 Jan. 2017.

McCarthy, T. 2014, Dec. 18. "Writing Machines." London Review of Books 36.24. 21-22. Retrieved from https://www.lrb.co.uk/v36/n24/tom-mccarthy/writing-machines. 2 Feb. 2017.

—. 2015. Remainder. Richmond: Alma Books.

Ray, R. B. 2011. "Impressionism, Surrealism, and Film Theory." Hill, J., and P. Church Gibson (eds.). Film Studies: Critical Approaches. Oxford: Oxford UP, 49-54.

Ricoeur, P. 2006. Memory, History, Forgetting. Trans. Blamey K., and D. Pellauer. Chicago: Chicago UP.

Saunders, G. 2017. Lincoln in the Bardo. London: Bloomsbury.

Schneider, A.-K. 2015. "The Naming of Love, or Reading Anne Enright's The Gathering against Derrida's The Politics of Friendship.” In: Childs, P., C. Colebrook and S. Groes (eds.). Women's Fiction and Post-9/11 Contexts. Lanham: Lexington Books, 81-94.

Sikov, E. 2010. Film Studies: An Introduction. New York: Columbia UP. 
Smith, A. 2012, Aug. 12. "Style vs Content: How Should Authors Approach the Task of Writing a Novel Today?" [Online video clip]. Edinburgh World Writers' Conference. Retrieved from https://www.youtube.com/watch?v=bHOSXziim9A. 15 Apr. 2017.

—. 2016. Autumn. London: Hamish Hamilton.

Smith, Z. 2009. "Two Directions for the Novel." In: Changing My Mind: Occasional Essays. New York: Penguin, 72-98.

Waugh, P., and J. Hodgson. 2012. "Introduction.” Review of Contemporary Fiction 32.3. 9-29. 